\title{
Applications of Lean Six Sigma in an Irish hospital
}

\author{
Abstract \\ Purpose \\ This paper presents a case study of the implementation of lean/ six sigma techniques through a series of student \\ projects carried out in a hospital setting.

\section{Design/methodology/approach} \\ The five projects were carried out by teams of masters student taking a module on operations and quality \\ management. The students were all staff members of the hospital. The study analysed each of the five projects under \\ a number of headings: setting and context, approach, key success factors, benefits and lessons learnt. The analysed \\ projects were then examined to identify patterns among the projects.
}

\section{Findings}

All student projects adopted a single foundation methodology as the basis for the project but supported this with additional techniques from the lean/ six sigma stable. The primary methodology was lean in the case of three projects, six sigma in the case of one project and mistake proofing in the case of the final project. The most commonly used supporting techniques were process mapping, 7 wastes, $5 \mathrm{~S}$ and logic tree/ root cause which were each used in two of the five projects. Other techniques used were control charts, checklists and theory of constraints which were each used by one project team. Support from top management and regular communication with stakeholders were identified as key factors for success by three of the five project teams. All of the projects, although implemented during a time period of less than three months and by relatively novice users of lean six sigma techniques, yielded practical benefit to the hospital.

\section{Practical implications}

Lean / six sigma offers a variety of methodologies and techniques for use on a process improvement project. It is vital that the project team select for use those techniques which are most appropriate to the particular context of the project. Adoption of an overall methodology (philosophy) supported by specific techniques proved to be an effective approach. Exposure to the various lean six sigma methodologies and techniques through education appeared to result in project teams selecting and using an appropriate set of techniques.

\section{Originality/value}

This paper provides useful information for practitioners who are introducing the lean six sigma approach into a hospital setting. The study demonstrates that relatively novice users of lean six sigma can provide value to the organization in a relatively short period of time. The study suggests that education and training in lean six sigma techniques is useful as it enables users to choose the right technique for the context and to use the technique in an appropriate manner. The paper also demonstrates that lean six sigma can be used and provide benefit in a variety of settings within a hospital.

Keywords: Lean, Six Sigma, Process, Healthcare, Ireland 


\section{Introduction}

Healthcare is a complex business that must continuously balance the need for medical care together with an attention to financial constraints. Although containing many pockets of excellence and demonstrating outstanding advances in technology and treatment, the healthcare sector is rife with inefficiencies and errors (Taner et al., 2007). Throughout the world financial pressures on healthcare have steadily increased over the past decade. While an ageing population and costly investments in technology are often cited as culprits for these financial pressures, operational inefficiencies are also a source of increased costs. These latter costs are largely under the control of healthcare professionals (De Koning et al. 2006).

Spiralling healthcare costs could result in a decreasing proportion of citizens in industrialized societies being able to afford high-quality healthcare (De Koning et al., 2006). One way to improve this situation is for the healthcare sector to examine its processes and to deliver care more efficiently and effectively within available budgets. The philosophy of continuous improvement and the techniques from the lean six sigma stable have a role to play in assisting healthcare deliver high quality service within its current budget constraints.

This paper examines a number of lean six sigma projects carried out in an Irish hospital by teams of masters students who were following a programme of leadership and change in healthcare. The projects were carried out as part of a course in operations and quality management. The students were tasked to examine and improve the efficiency and effectiveness of a clinical or an administrative process within the hospital. The paper is laid out as follows: section 1 looks at the literature on Lean Six Sigma and its application in healthcare; section 2 
reviews the individual projects, the methodology employed in each project,, the analysis carried out and the resulting improvments in the process ; section 3 provides a discussion and concludes.

\section{Lean Six Sigma}

Lean Six Sigma is a business improvement methodology that aims to maximize shareholder value by improving quality, speed, customer satisfaction, and costs: it achieves this by merging tools and principles from both Lean and Six Sigma. It has been widely adopted in manufacturing and service industries and its success in some famous organizations (e.g. GE, and Motorola) has created a copycat phenomenon with many organizations across the world willing to replicate the success.

Lean and six sigma have followed independent paths since the 1980s, when the terms were first hard coded and defined: the first applications of lean were recorded in the Michigan plants of Ford in 1913, and were then developed to mastery in Japan (within the Toyota Production System), while six sigma saw the light in the United States (within the Motorola Research Centre). Lean is a process improvement methodology used to deliver products and services better, faster, and at a lower cost. Womack and Jones (1996) defined it as:

a way to specify value, line up value-creating actions in the best sequence, conduct those activities without interruption whenever someone requests them, and perform them more and more effectively. In short, lean thinking is lean because it provides a way to do more and more with less and less - less human effort, less human equipment, less time, and less space-while coming closer and closer to providing customers with exactly what they want.

Six Sigma is a data driven process improvement methodology used to achieve stable and predictable process results, reducing process variation and defects. Snee (1999) defined it as: 
'a business strategy that seeks to identify and eliminate causes of errors or defects or failures in business processes by focusing on outputs that are critical to customers'.

While both lean and six sigma have been used for many years, they were not integrated until the late 1990s and early 2000s (George, 2002; George, 2003), and today lean six sigma is recognized as: 'a business strategy and methodology that increases process performance resulting in enhanced customer satisfaction and improved bottom line results' (Snee, 2010). Lean Six Sigma uses tools from both toolboxes, in order to get the best from the two methodologies, increasing speed while also increasing accuracy.

The benefits of lean six sigma in the industrial world, both manufacturing and service, have been widely highlighted in the literature (Antony, 2005a; Antony, 2005b) and include: ensuring that services and products conform to customer needs (i.e. hearing the 'voice of the customer'); removing non-value adding steps (waste) in critical business processes; reducing the cost of poor quality; reducing the incidence of defective products or transactions; shortening the cycle time; and delivering the correct product or service at the right time and place.

One of the key aspects differentiating Lean Six Sigma from previous quality initiatives is the organization and structure of the quality implementation functions. In quality initiatives prior to Lean Six Sigma, the management of quality was largely relegated to the production floor or, in larger organizations, to some statisticians in the quality department. Lean Six Sigma introduces a formal organizational infrastructure for different quality implementation roles, borrowing terminology from the world of martial arts to define hierarchy and career paths (Snee, 2004; Antony et al., 2005c; Antony et al., 2005d; Pande et al., 2000; Harry and Schroeder, 1999; Adams et al., 2003). 


\subsection{Lean Six Sigma in healthcare}

Six Sigma principles are well suited to the healthcare sector due to its zero tolerance for mistakes and Six Sigma's potential for reducing medical errors (Kwak and Anbari, 2004). At the same time, lean tools are applicable to an endless variety of processes in healthcare, addressing critical challenges such as medical errors, escalating costs and staffing shortages (Jimmerson et al., 2005). Lean and Six Sigma have the potential to contribute to the healthcare industry as much as they have contributed to the automotive industry (Manos et al., 2006).

Lean Six Sigma projects in healthcare have largely focused on direct care delivery, administrative support and financial administration (Antony et al., 2006). The aim has been to improve clinical processes, to identify and eliminate waste from patient pathways, to enable staff to examine their own workplace, and to increase quality, safety and efficiency (Fillingham, 2007; Silvester et al., 2004; Radnor and Boaden, 2008).

One of the first healthcare organizations to implement Six Sigma was Commonwealth Health Corporation in 1998 in the US state of Massachusetts (Thomerson, 2001). The implementation, facilitated by consultants from General Electric, gave positive results with a 33 per cent increase in radiology throughput and 21.5 per cent decrease in costs. Other US healthcare organizations have followed: Mount Carmel Health System in Ohio, Charleston Area Medical Center in West Virginia and Thibodaux Regional Medical Center in Louisiana (Sehwail and DeYong, 2003; Van den Heuvel et al., 2005). Mount Carmel reported a \$3.1 million savings achieved from their Six Sigma program (Lazarus and Stamps, 2002b), Charleston Area Medical Center achieved $\$ 841,000$ in savings on supply chain management by using Six Sigma (Lazarus and Stamps, 2002a), while Thibodaux Regional Medical Center reported savings of more than 
$\$ 475,000$ per year in 2001 and 2002 (Stock, 2002). Benedetto (2003) illustrates the Six Sigma approach at the University of Texas MD Anderson Cancer Center, while Elsberry (2000) describe how the same institution increased the number of examinations conducted by 45 per cent with no increase in resources (i.e. machines and shifts).

One of the first healthcare organizations outside the US to implement Six Sigma was the Red Cross Hospital in Beverwijk, in the Netherlands, with the assistance of the Institute for Business and Industrial Statistics at the University of Amsterdam: a total of $\$ 1.2 \mathrm{M}$ of savings was reported after three years of implementation (Van den Heuvel et al. 2004).

In the UK, the National Health Service (NHS) has applied both Six Sigma and lean (Proudlove et al., 2008). Lean is currently the focus of attention for the NHS with many of its principles included into the 'Productive Ward' initiative. In their study of the NHS Lean Six Sigma implementation Proudlove et al. (2008), having highlighted the difficulties in identifying customers and processes in healthcare settings and the importance of using clear and appropriate terminology, underlined the scope for a more unified presentation of process improvement approaches.

Since those first examples the use of Lean Six Sigma in healthcare has now spread. Success stories include improving timely and accurate claims reimbursement (Lazarus and Butler, 2001), streamlining the process of healthcare delivery (Ettinger, 2001) and reducing the inventory of surgical equipment and related costs (Revere and Black, 2003). Projects have been carried out in a variety of healthcare settings including frontline departments (e.g. emergency room, X-ray department, day cases), support services (inpatient and outpatient diagnostics), back office (e.g. medical records, medical reports, clinical coding), administration (e.g. billing errors, 
cost reduction, productivity improvement), cross-departmental projects (e.g. patient falls, medical and medication errors) and in broad hospital enhancements such as cost reduction, productivity improvement, bed availability and employee retention (Taner et al., 2007).

While implementation of Lean Six Sigma projects in healthcare meets similar barriers as for other industries, two challenges specific to healthcare are relevant: measurement and workforce psychology. With respect to measurement, in healthcare it is often difficult to identify processes which can be measured in terms of defects (Lanham and Maxson-Cooper, 2003). With regards to psychology of the workforce it is important to avoid use of business jargon when dealing with healthcare professionals else there is a risk of rejection or acceptance tinged with cynicism.

\section{Use of lean six sigma in a hospital context - case studies}

This section discusses five Lean Six-Sigma mini projects that took place in a large semiurban hospital in Ireland. The hospital provides emergency and acute care services across 54 medical specialties to a local community of some 290,000 people. It has 820 beds, employs approximately 3,500 staff, and is also a major teaching hospital. At time of writing a group of managers from the hospital, many holding senior positions, were attending a master's program on organizational change and leadership development delivered by a major university. Students were expected to act as leaders of change within their departments and also as ambassadors for change within the hospital as a whole. One element of this program was a course on quality and operations management. As part of the course students had to carry out a process improvement project within their area of responsibility, applying the quality and operations management tools covered within the module. This project allowed the students the opportunity to effect real 
change in the organization using techniques learnt. As students were simultaneously taking a module on leadership the project also afforded students the opportunity to act as leaders of change in the hospital.

The projects took place in different units within the hospital and involved a range of process improvement approaches and techniques. Five projects were selected for discussion in this paper on the basis that together they used a variety of Lean Six Sigma techniques and applied these techniques in a variety of organizational situations. The data for the five case studies presented in the paper came from: 1) full presentations by students on their projects in class, 2) summary presentations by the students to hospital senior management and 3) written project reports. The first and third items formed part of the formal assessment for the module. The second item was one of the mechanisms used to introduce course learning to the organization as a whole. Taken together the projects demonstrate how application of relatively simple techniques, supported by skills in leading change, can provide significant organizational value in a variety of ways.

The five projects are now discussed. Each project is discussed under four major headings: setting and context, approach, key success factors, benefits and lessons learnt. These heading were determined by the researchers from an examination of the projects. They were found to be the common denominators for the five projects and together provide a comprehensive picture of the project and its impact on the organization. Table 1 provides a brief summary of the projects. 


\begin{tabular}{|c|c|c|c|}
\hline Project & Method & $\begin{array}{l}\text { Supporting } \\
\text { techniques }\end{array}$ & Key Success Factors \\
\hline Ward Inventory & Lean & $\begin{array}{l}5 \mathrm{~S} \\
\text { Video }\end{array}$ & $\begin{array}{l}\text { Regular communication with internal } \\
\text { and external stakeholders }\end{array}$ \\
\hline Medical Records & $\begin{array}{l}\text { Six Sigma } \\
\text { (DMAIC) }\end{array}$ & $\begin{array}{l}\text { TOC } \\
\text { Logic Tree } \\
\text { Checklist }\end{array}$ & Support of departmental management \\
\hline $\begin{array}{l}\text { Laboratory } \\
\text { Processes }\end{array}$ & Lean & $\begin{array}{l}7 \text { Wastes } \\
5 \mathrm{~S} \\
\text { Process mapping } \\
\text { Load levelling }\end{array}$ & $\begin{array}{l}\text { Involvement of scientific staff } \\
\text { Clear communication of project } \\
\text { objectives }\end{array}$ \\
\hline Fall Prevention & $\begin{array}{l}\text { Mistake-proofing } \\
\text { (poka yoke) }\end{array}$ & $\begin{array}{l}\text { Control Chart } \\
\text { Root cause } \\
\text { analysis }\end{array}$ & $\begin{array}{l}\text { Availability of data } \\
\text { Signal from higher management of } \\
\text { project importance }\end{array}$ \\
\hline $\begin{array}{l}\text { Psychiatric } \\
\text { Clinic }\end{array}$ & Lean & $\begin{array}{l}\text { Process Mapping } \\
7 \text { Wastes }\end{array}$ & $\begin{array}{l}\text { Support of senior management } \\
\text { Commitment of process team to the } \\
\text { changed process } \\
\text { Support for change of IT infrastructure }\end{array}$ \\
\hline
\end{tabular}

Table 1: Summary of project methods, supporting techniques and key success factors

\subsection{Using $5 S$ to manage ward inventory}

Setting and context: This process improvement project examined and implemented change in the store-room of a busy hospital ward using the $5 \mathrm{~S}$ framework, a workplace organization method that uses a checklist of five Japanese concepts: seiri, seiton, seiso, seiketsu, and shitsuke (all beginning with the letter $\mathrm{S}$ and hence known as the 5S's). These concepts 
respectively refer to: sorting out the important from the unimportant, arranging items in a logical order within the workspace, cleaning and sweeping the workspace, identifying items in a standardised fashion, and sustaining the new order (Pranckevicius et al. 2003). Before the project commenced the store was over-crowded with many items missing, redundant, or difficult to access resulting in wasted effort, delay and staff frustration.

Approach: The project was implemented over a period of two weeks and followed the 5S's in the usual order (Ho, 1999). The students made a video movie of the store-room before and after process improvement took place. This video proved to be very effective in demonstrating the ex-ante need for improvement in the stores process and the ex-post improvement as a result of the project.

During the first or seiri stage all items in the store-room were examined. Those items that were no longer required or fit for use were removed or returned to the main hospital store. Indeed, several items were uncovered that had never been used in the ward. At the end of this stage the store-room contained significantly fewer items and clutter was removed. During the second or seiton stage items were re-arranged in the store and located in the most appropriate place. Items that tended to be used together were located together. At the end of this stage items remaining in the store were arranged in a convenient and logical order. During the third or seiso stage a new arrangement was put in place for ongoing cleaning of the store-room. During the fourth or seiketsu stage a standard format was introduced: each category of items was labelled and colour-coded. These standards signified the importance of the item to the ward but also ensured that the item would continue to be stored in its allocated place. At the end of the four stages items relevant to the work of the ward were easily accessible, clean and presentable, and easily identified using visual standards. At time of writing the fifth stage shitsuke is being 
implemented. This stage requires that the new approach be sustained into the long run. There is always a danger that people become used to the new development and gradually take it for granted. At this stage people can become lax in their ongoing implementation of the new store procedures; the store then gradually regresses to where it had been. Developing the discipline to sustain the $5 \mathrm{~S}$ stages will require ongoing communication within the ward and with the main store room personnel who work with the ward porter in replenishing the store.

Key success factors: Several steps were taken to ensure a successful implementation of the $5 \mathrm{~S}$ project. Firstly the stakeholders within the ward - nurse, healthcare assistants and porters - were briefed on the nature of the project and introduced to the $5 \mathrm{~S}$ framework. Secondly, the stakeholders within and without the ward were kept continually briefed on the progress of the project. This strategy of regular communication and explanation was vital in getting all stakeholders within the ward and the staff in the main hospital store on board and then keeping them on board. Lastly, the project had a champion in the form of a master's degree student who had learnt the 5S framework and other tools and techniques of process improvement. Also, the project was legitimised to a certain extent as it was being carried out as part of the assessment for a master's program that had the support of hospital senior management.

Benefits and lessons learnt: The project resulted in a storeroom that was clean, neat, appropriately stocked and fit for purpose. Among the lessons learnt were that change is a sociotechnical process and that correct management of human factors, for example identification of and communication with stakeholders, is as important as correctly carrying out the technical elements of a project. 


\subsection{Using DMAIC to improve provision of medical records}

Setting and context: Medical records hold important patient information and are regularly consulted during treatment. Ensuring that medical records are available at the required time and place is crucial to the effective running of hospitals. The project team examined a persistent problem with medical records in the hospital: medical records were not always available at the time and place of scheduled elective surgery leading to delay, non-value adding search activity, and possible cancellation of a procedure.

Approach: The student team used a number of different process improvement techniques in conjunction in order to deal with this problem situation. They used the DMAIC methodology from the six-sigma stable of techniques in order to manage and control the overall project (Pyzdek, 2003:237; Schroeder et al, 2008). They also used specific additional techniques during each of the DMAIC stages. For example, in the Define stage, they used the theory of constraints (Blackstone, 2001) to identify main blockages and bottlenecks in the process. Indeed, the definition of the project itself resulted from the implicit identification of a major constraint that stops the elective surgery process: the absence of a medical record for the patient. They also determined other constraints on the process, for example late additions of patients to the surgery schedule. In the Measure stage they defined a metric for process failure (medical record not available at scheduled time of surgery) and measured the success rate for the process. The students also estimated the financial cost of defects (mainly professional time wasted). In the Analysis stage they used logic trees (Blackstone, 2001) to identify root causes for the unavailability of medical records and then cross-referenced these against effects using a causeeffect matrix. This stage identified additional key process input and output variables and allowed the team produce a small number of 'critical to quality' statements. During the Improve stage 
they devised checklists and follow-up procedures to ensure medical records were available when needed. Within the Control stage the new process was documented and ongoing monitoring, measurement, control and communications procedures were put in place in conjunction with the relevant stakeholder departments.

Key success factors: Crucial to the success of the project was the identification of core issues relevant to the current process. Two core issues were identified: 1) human error and 2) the lack of a clear communication path between the relevant departments. Checklists were put in place to reduce the number of defects attributable to human error; these checklists facilitated dealing with the unexpected and identifying errors. Follow up procedures were designed and put in place to formalise communications between the medical records and surgical departments; in particular inter-departmental communication protocols for dealing with non-standard cases such as late additions to the surgery list.

Benefits and lessons learnt: The project demonstrated clear improvements to the process that proved to be of direct benefit to both medical records and surgical departments. Prior to implementation, defects were recorded at 28 out of 90 i.e. 28 medical records were unavailable at the scheduled time for surgery. Defects post-implementation were measured at 5 out of 220 i.e. only five medical records were unavailable when required at surgery. A key lesson learnt by students was that it is possible and indeed beneficial to use a variety of techniques in conjunction when carrying out a process improvement project. Students also learnt that it is useful to employ a guiding methodology, in this case DMAIC. 


\subsection{Applying a lean approach to laboratory processes}

Context and setting: This case study concerns the introduction of a lean approach to the chemical pathology laboratory activities. This is a busy unit of the hospital comprising 30 staff and receiving 3,500 samples daily from supplying clinicians. Laboratories provide a vital support service to clinicians and smooth running of laboratory processes is essential for effective support.

Approach: The project concentrated on the elimination of waste and the primary technique used was that of the 'seven wastes' (Imai, 1986:89; Ohno, 1988:151). Each type of waste was examined in turn, sometimes with the use of another supporting technique. For example, when examining defects the implementation team used the DMAIC methodology from the Six Sigma stable to systematically measure variation and reduce waste due to defects in the laboratory testing process; the project concentrated in particular on the reduction of the number of tests that had invalid results. When examining the issue of excess inventory the team used just-in-time as a basis for determining the supply of reagents used in laboratory testing; this resulted in a much smoother ordering cycle and significant reduction in the cost of ordering. However, as JIT requires smooth usage of materials occasional stock-outs of reagent have occurred since the introduction of the new system. When examining waste due to un-necessary motions the team used the $5 \mathrm{~S}$ approach to ensure that all equipment, vessels, tools, materials etc. were actually required, had a place, were in their place, that the place was clean, tidy and orderly, and that formal procedures were in place and were followed. To reduce waste due to waiting, transport and un-necessary steps in processing the team mapped processes, recorded the receipt of inputs (samples) and are attempting to level workload so that work is more evenly across the day and week. 
Key success factors: Two key success factors for the project were noted. Firstly, laboratory scientists must be involved in the process improvement project from the beginning. This did not happen in the case of this particular project and full benefits of the project were slower to be gained as a result. Secondly, project objectives need to be stated clearly from the outset. Again, this did not happen in the case of this particular project leading to suspicion among laboratory staff about the real motivation for the project. Whereas ostensibly the focus of the process improvement project was on cost reduction through elimination of waste, laboratory staff believed that staff reduction was an undeclared objective of the project. This led to slow engagement by laboratory staff in process improvement and delayed the gain of full benefit from the project.

Benefits and lessons learnt: Again in this project students learnt that it can be useful to combine the use of techniques but also to work within a specified framework, in this case the seven wastes. Interestingly, students used DMAIC as a subsidiary technique within the seven wastes. Although this is a somewhat irregular usage of DMAIC it proved to be effective for the students.

\subsection{Analysing fall prevention in an acute hospital setting}

Context and setting: This project set out to examine the impact of a fall reduction project that has been taking place in the hospital since 2008 . The original project set out to reduce the number of patients falling in the hospital. Falls are serious incidents and can lead to fractures which are painful and distressing for the patient and costly for the hospital. The risk of a patient falling is greater in hospital than at home because the person may be unfamiliar with the environment, weak due to their illness, and in poor control of their balance due to medication. Hospitals take the issue of falls seriously and undertake efforts to reduce the number of falls. The 
incidence of falls is typically measured as the number of occurrences per 10,000 patient days. An analysis of the impact of the program could be used to support its continuation in the hospital.

Approach: The project team adopted the philosophy of 'mistake proofing' (Grout, 2006) as a basis for examining the effectiveness of the existing hospital falls prevention project. Grout's (2007) criteria for good hospital mistake proofing designs are that they should be inexpensive, adaptable and easy to implement; they should also involve the patient's family or carer.

A specific objective of the project team was to identify high risk areas. To do this the project team used control charts (Mohammed et al, 2001) to examine existing levels of falls in two wards that had higher than average incidences of falls. The team examined monthly falls data over a two year period and used control charts to measure the variability of the process over time. The project team used the charts to determine when the process was out of control and attempted to determine the sources of 'special cause' variation. For example, one period of special variation coincided with the imposition of budgetary constraints that resulted in reduction in the availability of agency nursing staff.

The project team also recast the initiatives undertaken within the fall prevention program using a mistake proofing viewpoint. For example, one of the interventions introduced was to place an orange fall alert band on the wrist of patients who had already fallen or have a high likelihood of falling. The team recast this initiative as a 'mistake prevention' technique with the purpose of making others aware that the patient may require assistance. The project team demonstrated that this mistake prevention device met Grout's criteria: it was cheap, easy to implement, and provided a signal to the patient's family as well as to hospital staff. Such recasting alerted hospital staff to the nature and purpose of specific fall prevention initiatives 
thereby increasing their impact. Mistake proofing, also known as poka yoke, is a technique whereby an item is designed to be used in only one possible way. The purpose of this is to ensure that an item cannot be misused or mis-fitted. A box lid that has four different sides so that it fits onto the box in only one possible way is an example of a poka-yoke design. Mistake proofing supports a lean philosophy in that it seeks to reduce rework or poor work due to mistakes.

Key success factors: The availability of data from the ongoing falls prevention project was a key factor in enabling the project team to analyse falls data using control charts. Emphasis by higher management of the importance of falls prevention also helped ensure project success.

Benefits and lessons learnt: Assessment and prevention of patient falls has become an active part of best-practice nursing care in the hospital since implementation of the falls prevention project. The student project assisted this process by producing figures and charts that highlighting the impact of the falls reduction program in two specific wards. The student project provided a number of additional benefits for the hospital. It generated awareness in the hospital of the importance of 'mistake proofing' as an approach to falls prevention and an awareness of the four distinct elements of mistake proofing: mistake prevention, mistake detection, fail-safing, and error prevention. It also provided a theoretical grounding for falls prevention work that was already being carried out; for example, it pointed out that use of orange bands was a mistakeprevention technique. It demonstrated to hospital management the usefulness of control charts as an analytical tool and the important difference between the two sources of variation: common causes and special causes. The visual control charts clearly pointed out to management that keeping a process under control, in this case sustaining the reduction in the number of falls, remains a constant challenge. Finally the project made a number of practical recommendations to management including determination of fall control limits for specific wards, focusing fall 
reduction efforts on wards most at risk, and using control charts on a regular basis to review fall rates.

\subsection{Lean processes in a psychiatry clinic}

Context and setting: This project examined the effectiveness of written communication on patient care plans between a Clozapine clinic and its various outside stakeholders: community mental health teams, general practitioners, and patient care teams. Clozapine is a medicine that is very effective in treating schizophrenia but that can also have a number of serious, potentially life-threatening, adverse effects. Use of Clozapine is highly controlled and the process incorporates a number of mistake-proofing measures: patients must be registered with the Clozapine Patient Monitoring System and only psychiatrists and pharmacists registered with the system can prescribe and dispense it.

Approach: The project adopted a lean philosophy as the main broad approach and used value stream mapping to examine the written communications process in detail. Value stream mapping (sometimes called process mapping) is a technique whereby the steps in a process are identified and drawn on a map, somewhat similar to a flowchart. There are a number of conventions that can be followed in developing this map for example IDEF, originally developed by the US Military, or by the American Society of Mechanical Engineers (ASME). The map is then analysed and activities categorised, for example as value-adding, non-value adding or control.

The key actors in the process - psychiatrists, nurses, pharmacists, secretaries - were interviewed, the 'as-is' process from patient interview to posting of letter was mapped, and the process and lead times were determined. While the process time was of the order of a few hours, 
the total lead time for the process was found to be 15 days which was deemed too long and therefore unacceptable.

The project identified a number of non-value adding activities, for example the printing off of draft letters. The project team identified a number of un-necessary delays, for example waiting until the next Clozapine clinic, one week away, to read and approve draft letters. The process was redesigned and drawn up as a 'to-be' process map. In the redesign non-value adding activities such as printing off and correcting draft letters were removed, waiting for two oneweek periods between clinics was eliminated, and the IT infrastructure was altered to allow draft letters be edited directly on the clinic's server.

Key success factors: Commitment of the clinic staff to process improvement and a willingness to implement the revised process was critical to the success of the project. Support of the hospital IT group in making a number of relatively minor information technology changes also helped the project.

Benefits and lessons learnt: The lead time for the written communication process was reduced to 3 days, down from 15 days, and required no increase in cost or resources applied. The reduction in lead time meant that the overall care team had full knowledge of the patient care plan almost two weeks earlier than before. It reduced the number of queries coming into the clinic from patients, general practitioners and community mental health teams. The new process also freed up clinic staff time as several non-value adding tasks, for example correcting draft letters, were eliminated. This freed up time was used for other, value adding, purposes such as more time for the psychiatrist to spend with patients and more time for the secretary to deal with other backlogs. 


\section{Discussion and conclusion}

The projects discussed in this case study were all carried out by students who had taken one module on operations and quality management on a master's degree program in leadership and organisational change. While all students were experienced professionals in the hospital many came from clinical areas and were relatively new to lean concepts. The case study demonstrates that lean six sigma projects can yield considerable organizational benefit even when implemented by relatively novice users. Benefits of the projects ranged from a reduction in hospital falls, to more complete medical records and to reduction in prescription lead times. While the immediate benefits of the projects were to address operational matters, many of the project teams went on to make detailed recommendations for broader, more general improvements to the function concerned. Reflection back on learning was an integral part of the academic program and one of the intentions of the program is that students bring their learning to bear on their professional and their managerial contexts. The projects demonstrate that the combination of socio-technical skills - the technical process improvement skills to analyse an existing situation and design a new process, coupled with the leadership skills to implement change - makes for a powerful combination. The case study also demonstrated that lean projects can be effectively applied in many different areas of a hospital - wards, clinics, administration and are useful in pursuing many different purposes: streamlining stores operation, redesigning work processes and examining existing project effectiveness.

Leadership was also a key factor in successful projects. The importance of leadership demonstrated itself in two distinct ways. Firstly the support of organisational leaders was important for the successful implementation of process change. This support manifested itself through signals from senior management and through the active support of departmental 
managers. Secondly the leadership skills of the students themselves were enhanced via other modules on the program and these skills were utilised and further honed within the project teams.

There were several common threads in the way that students approached their practical projects. The student teams selected a main methodology and used this as an anchor for their project; this provided the project with a philosophy on which to base change. This anchor methodology was supported by specific techniques that were used to actually carry out the change. Most of the projects choose lean as the broad methodology with one team selecting six sigma/ DMAIC. There was also much commonality in the use of supporting techniques. Several projects used the $5 \mathrm{~S}$ technique to impose order on a process. Several projects used the 7 wastes to eliminate waste. Several projects used process mapping to analyse an existing process and identify value and non-value adding activities. Several projects used root cause analysis to identify fundamental process flaws. Other techniques used in a supporting fashion were theory of constraints, checklists and control charts.

The case study gives some insight into technique selection and usage. It suggests that it is useful to select techniques in a pragmatic fashion: if it works use it. It suggests that it is possible to combine techniques so long as they are compatible with or supportive of one another. It suggests that only one methodology should be selected to act as anchor, that is as the main controlling mechanism or philosophical underpinning for the project; other techniques may be used but in a supplementary or subsidiary fashion. The case study also suggests that a technique can act as anchor or as support depending on how it is used. For example, project two used DMAIC as a main methodology whereas project three used it as a supporting technique. Students were not guided as to what approach to take in carrying out their project but were given a free hand to select whatever technique they thought appropriate. An interesting topic for further 
research is to consider why students chose a particular technique as anchor: is it because it is most familiar to them, or because it seems easier to use, or because it is deemed most appropriate to the task at hand, or because they want to learn how to use it?

The application of Lean Six Sigma in healthcare is still at a relatively early stage compared with its use in manufacturing. Healthcare, in Ireland and in many countries, is currently subject to smaller budgets, reduced staffing but also increasing activity due to an aging population. Lean six sigma offers a way for healthcare to respond to this situation, not by seeking higher budgets or more resources, not by reducing activity or service levels, but by improving the way work is done. As the projects outlined in this paper illustrate, even relatively simple but appropriately implemented lean six sigma projects can produce organizational benefits such as better operational efficiency, higher process quality, improved cost-effectiveness and better value for money. Early successes in simple projects may pave the way for tackling more complicated initiatives in the future initiating a positive cycle of improvement with the potential to bring about healthcare process change on a broader scale. Arguably a single module on a masters program in healthcare leadership and organisational change is insufficient to bring about largescale process change in a single hospital in particular or to the Irish healthcare sector in general but it is a start, and as these projects demonstrate it provides a set of tools, techniques and effective methods for instigating process change. 


\section{References}

Adams, C., Gupta, P. and Wilson, C. (2003) Six Sigma Deployment. Burlington, MA, Butterworth-Heinemann.

Antony, J. (2005a) Assessing the status of six sigma in the UK service organizations. Proceedings of the Second National Conference on Six Sigma, Wroclaw, pp. 1-12.

Antony, J. (2005b) Six sigma for service processes. Business Process Management Journal, 12(2), 234-248.

Antony, J., Kumar, M. and Madu, C.N. (2005c) Six Sigma in small and medium sized UK manufacturing enterprises: some empirical observations. International Journal of Quality \& Reliability Management, 22(8), 860-874.

Antony, J., Kumar, M. and Tiwari, M.K. (2005d) An application of Six Sigma methodology to reduce the engine overheating problem in an automotive company. IMechE-Part B, 219(B8), 633-646.

Antony, J., Antony, F. and Taner, T. (2006), “The secret of success", Public Service Review: Trade and Industry, Vol. 10, 12-14.

Antony, J., Kumar, M. and Cho, B.R. (2007) Six Sigma in services organizations: benefits, challenges and difficulties, common myths, empirical observations success factors. International Journal of Quality Reliability Management, 24(3), 294-311.

Benedetto, A.R. (2003), "Adapting manufacturing-based six sigma methodology to the service environment of a radiology film library", Journal of Healthcare Management, 48(4), 263-280

Blackstone J.H. 2001. Theory of constraints - a status report. International Journal of Production Research 39(6), 1053-1080.

De Koning, H., Verver, J. P. S., Van den Heuvel, J., Bisgaard, S. and Does, R. J. M. M. (2006) Lean Six Sigma in Healthcare. Journal for Healthcare Quality, 28(2), 4-11.

Fillingham, D. (2007), “Can lean save lives?”, Leadership in Health Services, 20(4), 231-41.

Elsberry, R.B. (2000), "Six sigma: applying a corporate model to radiology", Decisions in Imaging Economics, 13(7), 56-66

Ettinger, W. (2001), “Six sigma adapting GE's lesson to health care”, Trustee, 54(8), 10-16.

George, M.L. (2002) Lean Six Sigma - Combining Six Sigma Quality with Lean Speed. New York, NY, McGraw-Hill.

George, M.L. (2003) Lean Six Sigma for Service - How to Use Lean Speed and Six Sigma Quality to Improve Services and Transactions. New York, NY, McGraw-Hill.

Grout, J.R. (2006). Mistake proofing: changing designs to reduce error. Quality and Safety in Healthcare, 15(Suppl I), i44-i49. 
Grout, J.R. (2007). Mistake-Proofing the Design of Health Care Processes. Agency for Healthcare Research and Quality - AHRQ Publication 7(20), 1-22.

Harry, M. and Schroeder, R. (1999) Six Sigma - The Breakthrough Management Strategy Revolutionizing the World's Top Corporations. New York, NY, Doubleday.

Ho S. 1999. 5-S practice: the first step towards total quality management. Total Quality Management 10(3), 345-356.

Kwak, Y.H. and Anbari, F.T. (2004)'Benefits, obstacles, and future of six sigma approach", Technovation, 26(5/6), 708-715

Imai M. 1986. Kaizen: the key to Japan's competitive success. New York: Random House.

Jimmerson, C., Weber, D. and Sobek, D. K. (2005) "Reducing Waste and Errors: piloting Lean principles at Intermountain Healthcare", Journal on Quality and Patient Safety, 31(5), 249-257

Lanham, B. and Maxson-Cooper, P. (2003), "Is six sigma the answer for nursing to reduce medical errors?", Nursing Economics, 21(1), 39-41.

Lazarus, I.R., Butler, K., 2001. "The promise of six sigma”, Managed Healthcare Executive, 11(9), 22-26

Lazarus, I.R. and Stamps, B. (2002a) 'The promise of Six Sigma: getting better faster', Extra Ordinary Sense, 3, 3-29.

Lazarus, I.R. and Stamps, B. (2002b) 'The promise of Six Sigma', Managed Healthcare Executive, 12, 27-30.

Manos, A., Sattler, M. and Alukal, G. (2006) "Make Healthcare Lean”, Quality Progress, 39(7), 24-30.

Mohammed, A.M., Cheng, K.K., Rouse, A, Marshall, T. (2001). "Bristol, Shipman, and clinical governance: Shewhart's forgotten lessons”. The Lancet, 357, 463-467

Ohno T. 1988. Evolution of the Toyota Production System in Robinson A. (Ed.). Continuous improvement in operations: a systematic approach to waste reduction. Cambridge, MA: Productivity Press, 1991.

Oliver, D., Britton, M., Seed, P., Martin, F.C., Hopper, A.H. (1997). Development and evaluation of evidence based risk assessment tool (STRATIFY) to predict which elderly inpatients will fall: case-control and cohort studies. British Medical Journal, 315(7115), 10491053.

Pande, P., Neuman, R. and Cavanagh, R. (2000) The Six Sigma Way: How GE, Motorola and Other Top Companies Are Honing their Performance. New York, NY, McGraw-Hill Professional.

Pyzdek T. 2003. The six sigma handbook. New York: McGraw-Hill. 
Pranckevicius, D., Diaz, D. M. \& Gitlow, H. (2003) “A Lean Six Sigma case study: an application of the "5S" techniques", Journal of Advances in Management Research, Vol. 5, No. 1, pp. 63-79

Proudlove, N., Moxham, C. and Boaden, R. (2008) 'Lessons for Lean in Healthcare from using Six Sigma in the NHS', Public Money and Management, 28(1), 27-34.

Radnor, Z. and Boaden, R. (2008), "Editorial: Does lean enhance public services?", Public Money and Management, 28(1), 3-6.

Revere, L., Black, K. (2003), "Integrating six sigma with total quality management: a case example for measuring medication errors", Journal of Healthcare Management, 48(6), 377-391

Schroeder R.G., Linderman K., Liedtke C., Choo A.S. 2008. Six sigma: definition and underlying theory. Journal of Operations Management 26(4), 536-554.

Sehwail, L. and DeYong, C. (2003) 'Six Sigma in health care', International Journal of HealthCare Quality Assurance Incorporating Leadership in Health Services, 16, pp.i-v.

Snee, R. D. (1999) Why should statisticians pay attention to Six Sigma? Quality Progress, 32(9), $100-103$.

Snee, R.D. (2004) Six Sigma: the evolution of 100 years of business improvement methodology. International Journal of Six Sigma and Competitive Advantage, 1(1), 4-20.

Snee, R. D. (2010) Lean Six Sigma - getting better all the time, International Journal of Lean Six Sigma, 1(1), 9-29.

Silvester, K., Lendon, R., Bevan, H., Steyn, R. and Walley, P. (2004), "Reducing waiting times in the NHS: is lack of capacity the problem?", Clinician in Management, 12(3), 105-11.

Stock, G. (2002) 'Taking performance to a higher level', Six Sigma Forum Magazine, 1(3), 2326.

Taner, M. T., Sezen, B. and Antony, J. (2007) An overview of Six Sigma applications in healthcare industry. International Journal of Health Care Quality Assurance, 20(4), 329-340

Thomerson, L.D. (2001) 'Journey for excellence: Kentucky's Commonwealth Health Corporation adopts Six Sigma approach', Annual Quality Congress Proceedings, 55, 152-158.

Van den Heuvel, J., Does, R.J.M.M. and Vermaat, M.B. (2004) 'Six Sigma in a Dutch hospital: does it work in the nursing department?', Quality and Reliability Engineering International, 20, 419-426.

Van den Heuvel, J., Does, R.J.M.M. \& Verver, J.P.S. (2005), 'Six Sigma in healthcare: lessons learned from a hospital', International Journal of Six Sigma and Competitive Advantage, 1(4), 380-388.

Womack, J. P. and Jones, D. T. (1996) Lean Thinking. New York, NY, Simon \& Schuster. 